\title{
Cost effectiveness of a community based research project to help women quit smoking
}

\author{
R H Secker-Walker, R R Holland, C M Lloyd, D Pelkey, B S Flynn
}

Tobacco Control 2005;14:37-42. doi: 10.1136/tc.2003.005470

See end of article for authors' affiliations ....

Correspondence to: Roger H Secker-Walker, $M D, 1$ South Prospect Street, Burlington, VT 05401, USA; roger. secker-walker@.uvm.edu

Received 28 July 2003 Accepted 4 August 2004
Objective: To estimate the cost effectiveness of a four year, multifaceted, community based research project shown previously to help women quit smoking.

Design: A quasi-experimental matched control design.

Setting: Two counties in Vermont and two in New Hampshire, USA.

Subjects: Women aged 18-64 years.

Methods: Costs were the grant related expenditures converted to 2002 US\$. Survey results at the end of the intervention were used to estimate the numbers of never smokers, former smokers, light smokers, and heavy smokers in the intervention and comparison counties, and 1986 life tables for populations of US women categorised by smoking status to estimate the gain in life expectancy.

Main outcome measures: Cost effectiveness ratios, as dollars per life-year saved, for the intervention only and for total grant costs (intervention, evaluation and indirect costs).

Results: The cost effectiveness ratio for the intervention, in 2002 US \$ per life-year saved, discounted at 3\%, was $\$ 1156$ (90\% confidence interval (CI) \$567 to $\infty$ ), and for the total grant, $\$ 4022$ (90\% Cl \$1973 to $\infty$ ). When discounted at 5\%, these ratios were $\$ 1922(90 \% \mathrm{Cl} \$ 1024$ to $\$ 15647)$, and $\$ 6683(90 \% \mathrm{Cl}$ $\$ 3555$ to $\$ 54422$ ), respectively.

Conclusion: The cost effectiveness ratios of this research project are economically attractive, and are comparable with other smoking cessation interventions for women. These observations should encourage further research and dissemination of community based interventions to reduce smoking. in cost benefit analyses concerned with health related interventions, the monetary cost of developing and implementing a particular intervention is compared to the monetary value of the benefits of that intervention. When a monetary value cannot be given to the major benefits of an intervention, cost effectiveness analysis is more appropriate. In interventions concerned with smoking cessation, cost effectiveness may be expressed in relation to a specific outcome, such as the cost per quitter. A more general approach is to estimate the benefits as the years of life saved by the intervention. Because these years are in the future, they are usually discounted at rates which have varied from $3-10 \%$. Cost effectiveness is then determined as the cost of the intervention per discounted life-year saved. This allows cost related comparisons and decisions to be made between different health related interventions. ${ }^{1-4}$

Among 32 recently reviewed experimental or quasiexperimental community based interventions which included smoking reduction as one of their aims, ${ }^{5}$ there were seven with cost effectiveness or cost benefit analyses. Two of these, the North Karelia project and Heartbeat Wales, reported both cost effectiveness and cost benefit analyses related to different aspects of their cardiovascular risk reduction programmes $^{67}$ - the hypertension programme and coronary heart disease disability in the North Karelia Project, ${ }^{89}$ and smoking reduction in Heartbeat Wales. ${ }^{10}$ The Norsjo project, another cardiovascular risk reduction project, reported cost effectiveness for its cholesterol lowering programme, ${ }^{11}$ and willingness to pay analyses related to the entire programme. ${ }^{12}$ Action Heart, another cardiovascular risk reduction project, reported on the cost effectiveness of its programme in reducing smoking. ${ }^{13}$ Comparisons between these cost effectiveness studies, or between the cost benefit studies, are fraught with difficulty largely because of differences in the methods used in each study. However, even with this uncertainty, each project reported either favourable cost effectiveness ratios, in terms of cost per life-year saved, or favourable cost benefit ratios.

Three other analyses, from the Stanford five-city project, ${ }^{14}$ the Pawtucket heart health programme, ${ }^{15}$ and the Dutch community study, ${ }^{16}$ concerned comparisons of the cost effectiveness of different smoking cessation interventions, conducted as part of their respective community programmes, in terms of cost per quitter. The results of each study allowed comparisons within each project as to which particular intervention was more cost effective than another in getting smokers to quit, but do not allow comparisons with other health related interventions.

We previously reported on a significant reduction in the prevalence of cigarette smoking and an increase in the quit rate among adult women, which accompanied a multifaceted, community based intervention targeted to women. ${ }^{17}$ Logistic regression analyses, adjusting for baseline differences between conditions, showed that after four years, compared to the comparison counties, the odds of being a smoker in the intervention counties were $0.88 \quad(95 \%$ confidence interval (CI) 0.78 to 1.00 ), one tailed $\mathrm{p}=0.02 .{ }^{17}$ The intervention, named Breathe Easy, which involved delivery of cessation services through support systems, health professionals, educators, work sites, and the media, and its evaluation were supported by a research grant from the National Institutes of Health. The research grant costs included the cost of the intervention, the cost of the evaluation, and the University of Vermont's indirect costs. Herein, we describe the cost effectiveness of that intervention from the perspective of the granting agency. This perspective includes the cost effectiveness of the intervention alone, and the cost effectiveness of the total grant monies awarded to the University of Vermont for this project. 


\section{METHODS}

The Breathe Easy project was undertaken in four counties, two in Vermont and two in New Hampshire. One county in each state received the intervention, while the other pair of demographically similar counties was the comparison area. The four year intervention and its efficacy, which was assessed by random digit dialling telephone surveys at baseline and year 5, at the end of the intervention, have been described in detail elsewhere. ${ }^{17-22}$ The costs of intervention development, implementation, and evaluation were derived from the actual expenditures of grant monies for these components of the research project. We summed the portion of salaries and fringe benefits of investigators and staff and the project operating expenditures related to each component for each of the five years. Intervention costs were the sum of development and implementation expenditures, and direct costs were the sum of intervention and evaluation expenditures. Indirect costs were those received by the University of Vermont to cover the general costs of supporting research, such as grant administration, heating, lighting, and security. Total grant costs were the sum of direct and indirect costs.

We used the consumer price index (CPI) to adjust all costs to 2002 US dollars (US\$2002), using the ratio of the 2002 CPI to the CPI for each of the years 1989-1993. ${ }^{23}$ In addition, all costs reported in the cost effectiveness studies referred to subsequently were adjusted to US\$2002, using the ratio of the 2002 CPI to the CPI for the year of the reported costs in each study.

\section{Population estimates}

We used the smoking behavioural results of the year 5 survey $^{17}$ and 1990 census population data for the two intervention counties to estimate the numbers of female never smokers, former smokers ( $>5$ years and $\leqslant 5$ years), light smokers $(<25$ cigarettes per day), and heavy smokers $(\geqslant 25$ cigarettes per day), ages 18-64 years, in five year age strata, except for seven years in the 18-24 year age group, using SUDANN software. ${ }^{24}$ These estimates were done for women in the intervention counties and in a modified comparison area constrained to have the same population and age distribution as the intervention counties, but the year 5 smoking behavioural results of the comparison counties.

\section{Estimates of life expectancy}

We used Microsoft Access to build a Monte Carlo life table model. ${ }^{25}$ This model used the number of women in each smoking category in each age group derived from our estimates of their respective population means and standard errors. We used published 1986 life tables for white female never, former, light, and heavy smokers to calculate the life expectancy for each smoking category in each age cohort. ${ }^{26}$ As the life table model runs, each age cohort with its smoking related categories is cycled to the next higher age stratum and then experiences the appropriate mortality rates of that stratum. This cyclical process continues upwards through each of the age strata in the life tables.

The reference life tables do not include mortality data for the 18-24 year age group. For this age cohort, in the base analysis, we assumed that there was no smoking related effect on life expectancy between ages 18 to 24 years, and used the 1986 mortality rate of white females for these ages from US Vital Statistics, ${ }^{27}$ regardless of this cohort's smoking status. When this cohort cycled up through the subsequent age strata, it experienced their appropriate smoking related mortality rates. The reference life tables also do not distinguish between recent and longer term quitters, so we regarded both categories as former smokers.
We used 10000 cycles of the model to determine the life expectancy for both the intervention and comparison populations. For the base case, life-years saved were discounted at $3 \%{ }^{28}$ Cost effectiveness ratios were then calculated as the cost per life-year saved for intervention costs and for total grant costs.

\section{Sensitivity analyses}

We conducted several sensitivity analyses. Because we lacked mortality data for the 18-24 year old cohort, we did two further estimates - one to provide a more favourable mortality experience for this age cohort than the base case, and the other a less favourable experience. For the first of these, we substituted zero mortality for the 18-24 year cohort until they cycled into the 25-29 year age stratum. For the second, we substituted the known mortality of each smoking category in the 25-29 year age stratum for the unknown mortality of the 18-24 year cohort, which then cycled up the age strata. In additional sensitivity analyses, we examined discount rates of $0 \%$ and $5 \%$; indirect cost recovery rates of $10 \%$ and $25 \%$; and community volunteer opportunity costs of $\$ 10 /$ hour and $\$ 25 /$ hour.

\section{Level of significance}

In reporting the results of the Breathe Easy project, a one tailed test of significance was used to assess differences between conditions, because the a priori main hypothesis was that more favourable changes would be observed in the intervention counties relative to the comparison counties. ${ }^{17}$ We have used that convention here.

\section{RESULTS}

\section{Personnel effort}

The full time equivalent (FTE) effort provided by faculty and staff at the University of Vermont during this research project (April 1989 through July 1993) was 8.3 (investigators, 1.8 FTE; research staff, 4.9 FTE; administrative staff, 1.6 FTE). Each of the two intervention counties had a community office staffed by three full time employees (a community coordinator, a health educator, and a secretary); thus the overall total staffing for the research group was 14.3 FTE.

\section{Costs}

All costs, derived from project expenditure records, were converted to US\$2002. For intervention development and implementation, personnel salaries and fringe benefits were $\$ 1348257$, consultant costs, \$29 799, and operating costs, $\$ 593$ 424, for total intervention costs of \$1 971480 . For evaluation, personnel salaries and fringe benefits were \$2 297467 , consultant costs, \$6544, and operating costs, $\$ 307895$, for a total of $\$ 2611906$. Direct costs, the sum of intervention and evaluation costs, were $\$ 4583$ 386. Indirect costs were \$2 273756 , so that total grant costs-that is, the sum of direct and indirect costs-were \$6 857142 .

\section{Population estimates}

The population of women in the two intervention counties was 35 243. Our estimates of the number of never smokers, former smokers ( $>5$ years and $\leqslant 5$ years), light smokers, and heavy smokers in the intervention counties and modified comparison area in 1993, at the end of the intervention, are shown in table 1.

\section{Cost effectiveness}

The life-years saved with no discounting and with 3\% and 5\% discounting are shown in table 2 . Life-years saved with no discounting and those at 3\% discounting were not significant, while those at $5 \%$ discounting were significant $(p=0.04)$. 
Table 1 Population estimates of never, former, light, and heavy smokers in 1993

\begin{tabular}{lccc}
\hline Smoking status & $\begin{array}{l}\text { Intervention } \\
\text { counties (I) }\end{array}$ & $\begin{array}{l}\text { Modified comparison } \\
\text { counties (C) }\end{array}$ & $\begin{array}{l}\text { Difference } \\
\text { (I - C) }\end{array}$ \\
\hline Never & 18472 & 18178 & 294 \\
Former $>5$ years & 5180 & 5188 & -8 \\
Former $\leqslant 5$ years & 3347 & 2794 & 553 \\
Light $<25$ cigs/day & 6648 & 7295 & -647 \\
Heavy $\geqslant 25$ cigs/day & 1596 & 1788 & -192 \\
Total population (women, ages 18-64) & 35243 & 35243 & \\
\hline & & &
\end{tabular}

Table 2 also shows the cost effectiveness ratios of this research project-that is, dollars per life-year saved-in relation to intervention costs, direct costs, and total grant costs, with no discounting and with $3 \%$ and $5 \%$ discounting. For both no discounting and 3\% discounting, the $90 \%$ confidence intervals included zero, leading to infinity for the upper limit of the related cost effectiveness ratios. The lower limit of the $90 \%$ confidence interval with 3\% discounting was -65 years, while that with 5\% discounting was 126 years.

\section{Sensitivity analyses}

In estimating life expectancy for the 18-24 year age cohort for the base case analysis, we used mortality rates for white females from the 1986 US life tables without regard to smoking status. Substituting zero probability of death for this age group until they reach 25-29 years, regardless of smoking status, a liberal assumption, increased the 18-24 year age cohort's life-years saved by 75 years compared to the base case, and reduced the cost effectiveness ratios by $4.2 \%$. Substituting the mortality experience of the 25-29 year age group, a conservative assumption, reduced the 18-24 year age cohort's life-years saved by 20 years compared to the base case, and increased the cost effectiveness ratios by $1.2 \%$.

This study was funded by the National Institutes of Health. The University of Vermont's indirect cost rate at that time was about $50 \%$. For grants from non-profit agencies, indirect cost recovery rates are usually substantially less than this, between $10-25 \%$. The cost effectiveness of the intervention alone, without evaluation, and of the intervention and evaluation combined with indirect costs at $10 \%$ and $25 \%$, with $3 \%$ and $5 \%$ discounting, are shown in table 3 . As would be expected, the ratios increase in proportion to the increase in costs.

Because our analysis was from the perspective of the granting agency, we did not include the opportunity costs of the numerous community volunteers who assisted with many aspects of intervention implementation in the base analysis. However, the time contributed by volunteers during the course of the project was at least 7500 hours, as determined from each community's monthly reports (Secker-Walker RH, unpublished data). At \$10/hour, these volunteer hours would add \$98 250 to the intervention costs, an increase of $5 \%$, and at $\$ 25 /$ hour they would add $\$ 245625$, an increase of $12.5 \%$. The cost effectiveness of the interven- tion alone, without evaluation, and of the total grant, with volunteer opportunity costs of $\$ 10 /$ hour and $\$ 25 /$ hour, with $3 \%$ and $5 \%$ discounting, are shown in table 3 . The ratios increase in proportion to the increase in costs.

\section{DISCUSSION}

The cost effectiveness ratios of Breathe Easy's community based smoking cessation intervention alone and of the research grant as a whole are economically attractive, although those obtained with 3\% discounting, the recommended rate, ${ }^{28}$ fell short of conventional statistical significance. In this study, the $90 \%$ confidence interval for the increase in life-years saved with 3\% discounting ranged from -65 to 3475 years. Thus, although the mean cost effectiveness ratios and lower $90 \%$ confidence intervals for the intervention alone and for the total grant at this discount rate could be estimated, the upper limit could not. We note that the probability that life-years saved was greater than zero, and hence the upper limit of the cost effectiveness ratios was finite, was $94 \%$.

Although the currently recommended discount rate for cost effectiveness analyses is 3\%, a sensitivity analysis using $5 \%$ is also recommended because many earlier cost effectiveness analyses used that rate. ${ }^{28}$ In this study, the increase in life-years saved with 5\% discounting was significant, the $90 \%$ confidence interval ranging from 126 to 1926 years. We note that three contemporary community based studies, two aimed at smoking cessation, the Stockholm Quit and Win Contest (1988), ${ }^{29}$ and Action Heart (1991-1995), ${ }^{13}$ and the other at lowering cholesterol, the Norsjo project (19851990), ${ }^{11}$ used discount rates of $5 \%, 6 \%$, and $5 \%$, respectively, in their cost effectiveness analyses.

This cost effectiveness analysis was from the perspective of the granting agency which funded this community based health education research project. Such granting agencies have a substantial interest in dissemination of successful projects. If the Breathe Easy intervention was widely adopted in other communities, the benefits of the investment in the research aspects of the project-that is, its evaluationwould extend beyond those achieved during this project. The inclusion of evaluation costs and indirect costs in our analysis, as others have done, ${ }^{29}$ overstates the cost per life-year saved that would result from replications of the intervention itself. A community based smoking cessation programme would incur local development and implementation costs,

Table 2 Life-years saved and cost effectiveness ratios for different discount rates

\begin{tabular}{|c|c|c|c|c|c|}
\hline \multirow{2}{*}{$\begin{array}{l}\text { Discount } \\
\text { rate }(\%)\end{array}$} & \multirow[b]{2}{*}{ Life-years saved $(90 \% \mathrm{Cl})$} & \multicolumn{4}{|c|}{ Cost effectiveness ratio: US\$2002 life-year saved (\$/LYS) } \\
\hline & & p Value* & Intervention \$/LYS (90\% Cl) & Direct costs $\mathbf{\$} /$ LYS $(90 \% \mathrm{Cl})$ & Total grant $\$ /$ LYS $(90 \% \mathrm{Cl})$ \\
\hline 0 & 3870 (-2100 to 9857$)$ & 0.15 & $509(200$ to $\infty)$ & $1184(465$ to $\infty)$ & $1772(696$ to $\infty)$ \\
\hline 3 & $1705(-65$ to 3475$)$ & 0.06 & 1156 (567 to $\infty)$ & $2688(1320$ to $\infty)$ & $4022(1973$ to $\infty)$ \\
\hline 5 & 1026 (126 to 1926$)$ & 0.04 & 1922 (1024 tol5647) & 4467 (2380 to 36376$)$ & 6683 (3555 to 54422 ) \\
\hline
\end{tabular}


Table 3 Results of sensitivity analyses

\begin{tabular}{|c|c|c|c|}
\hline & & \multicolumn{2}{|c|}{ Cost effectiveness ratio: US\$2002 per life-year saved (\$/LYS) } \\
\hline & & $\begin{array}{l}3 \% \text { discount rate } \\
\text { \$/LYS }(90 \% \mathrm{CI})\end{array}$ & $\begin{array}{l}5 \% \text { discount rate } \\
\text { \$/LYS }(90 \% \mathrm{CI})\end{array}$ \\
\hline \multicolumn{4}{|l|}{ Indirect costs } \\
\hline $10 \%$ & Intervention & $1272(624$ to $\infty)$ & $2114(1126$ to 17211$)$ \\
\hline $25 \%$ & Intervention & 1445 (709 to $\infty)$ & 2402 (1280 to 19558$)$ \\
\hline $10 \%$ & Total grant & 4424 (2171 to $\infty)$ & 7352 (3916 to 59864$)$ \\
\hline $25 \%$ & Total grant & 5027 (2467 to $\infty)$ & 8354 (4450 to 68027$)$ \\
\hline \multicolumn{4}{|c|}{ Volunteer costs } \\
\hline$\$ 10 /$ hour & Intervention & 1214 (596 to $\infty)$ & 2017 (1075 to 16426$)$ \\
\hline$\$ 25 /$ hour & Intervention & 1300 (638 to $\infty)$ & 2161 (1151 to 17596$)$ \\
\hline$\$ 10 /$ hour & Total grant & $4079(2002$ to $\infty)$ & 6779 (3611 to 55202$)$ \\
\hline$\$ 25 /$ hour & Total grant & 4166 (2044 to $\infty)$ & 6923 (3688 to 56372 ) \\
\hline
\end{tabular}

and modest indirect costs, and, if successful, could be as cost effective as the Breathe Easy intervention alone-that is, with cost effectiveness ratios between $\$ 1000-\$ 2000$ per lifeyear saved.

We used published life tables from 1986, the latest we could find with detailed smoking related mortality rates, to estimate life expectancy. ${ }^{26}$ These life tables predate the year 5 Breathe Easy survey by seven years. Since that time, the life expectancy of women has increased, ${ }^{31}$ so it is likely that the cost effectiveness of both the intervention alone and of the total grant would have been more favourable than our estimates.

\section{Sensitivity analyses}

Our base case estimate for the unknown mortality experience of the 18-24 year old cohort seems quite reasonable, giving a cost effectiveness ratio $4.2 \%$ greater than the "no mortality" estimate, and only $1.2 \%$ lower than that obtained using the smoking related mortality rates of the 25-29 year age group.

The other sensitivity analyses, related to indirect costs and volunteer opportunity costs, show the expected changes in cost effectiveness ratios in proportion to the increases in costs, resulting in relatively small changes to the cost effectiveness of the Breathe Easy project. For example, with $3 \%$ discounting, the mean cost effectiveness of the intervention alone, with indirect costs at 25\%, was \$1445 per life-year saved, and with volunteer opportunity costs at $\$ 25 /$ hour, the mean cost effectiveness ratio was $\$ 1300$ per life-year saved.

\section{Limitations}

There are several limitations to our analyses, some of which relate to the design of the original trial. First, the sample size for the original research project was not calculated with this cost effectiveness analysis in mind. Although there were 6436 respondents to the year 5 survey, ${ }^{17}$ the number in each of the five smoking categories in each of the nine age strata in each

\begin{tabular}{|c|c|c|}
\hline Smoking cessation intervention & $\begin{array}{l}\text { Discount } \\
\text { rate (\%) }\end{array}$ & $\begin{array}{l}\text { US\$2002 per } \\
\text { life-year saved }\end{array}$ \\
\hline Physicians' advice, $1984^{* 38}$ & 5 & 2094-3581 \\
\hline Plus nicotine gum, $1984^{* 37}$ & 5 & $11971-16483$ \\
\hline Plus transdermal nicotine, $1995^{* 39}$ & 3 & $5847-8240 \ddagger$ \\
\hline AHCPR guidelines, $1995 t^{41}$ & 3 & $1307-5360 \ddagger$ \\
\hline Stockholm Quit and Win contest, $1988 t^{29}$ & 5 & $1671-3749$ \\
\hline Present study - Breathe Easy, 2002* & 3 & $1156-4022$ \\
\hline Present study-Breathe Easy, 2002* & 5 & $1922-6683$ \\
\hline \multicolumn{3}{|c|}{ *For women; †for women and men; $¥ U S \$ 2002$ quality adjusted life- } \\
\hline
\end{tabular}

condition, from which the population estimates were made, was small, averaging 71.5 per cell (SD 71.0). Thus, the standard errors of these estimates were relatively large, contributing to the lack of significance of the life-years saved with $0 \%$ and $3 \%$ discounting. Second, this was a quasiexperimental, non-randomised design with only two pairs of matched communities in each condition. Randomised designs with eight or more matched pairs of communities, such as COMMIT and CART, allow for more robust analyses. ${ }^{32} 33$ Third, we did not include an estimate of lifeyears gained by non-smoking community members as a result of less exposure to secondhand smoke, thereby overstating, to a small extent, the cost per life-year saved of the Breathe Easy project. ${ }^{2}$

\section{Strengths}

There are several strengths to this study. First, we estimated life-years saved from published life tables for the intervention and modified comparison counties' populations, rather than the median, or a range of differences in life expectancy between smokers and non-smokers as used by others. ${ }^{13}{ }^{34}$ Second, for the original trial, the statistical comparisons matched the design - that is, the communities were the unit of analysis. ${ }^{35}{ }^{36}$ Third, the observed fall in smoking prevalence in the intervention counties was unlikely to be caused by secular trends. Most of the reduction in smoking took place among groups of women specifically targeted by the intervention, those with lower incomes and of childbearing age. ${ }^{17}$

\section{Comparisons with other studies}

Cost effectiveness ratios for smoking cessation interventions tend to be greater for women than men. ${ }^{37-39}$ As far as we are aware, the Breathe Easy Project is the only community based smoking reduction intervention specifically targeted to women for which there are published results, which makes direct comparison with other studies difficult. Although the Canadian trial, Coeur en Sante St Henri, a cardiovascular risk reduction project, had a special focus on women, there was no effect on smoking prevalence and no cost effectiveness analysis. ${ }^{40}$

As shown in table 4, the mean cost effectiveness ratios for the Breathe Easy Project are similar to those obtained for smoking cessation advice for women provided by physicians, ${ }^{38}$ and for the transdermal nicotine patch as an adjunct to physicians' advice, ${ }^{39}$ but substantially less than the use of nicotine gum as an adjunct to physicians' advice. ${ }^{37}$ Our cost effectiveness ratios are also similar to those reported for implementation of the Agency for Health Care Policy and Research (AHCPR) guidelines for smoking cessation interventions for both women and men. ${ }^{41}$ Strict comparison between these studies must be tempered by their use of 
differing discount rates, $5 \%$ in the earlier ones, ${ }^{37}{ }^{38}$ and 3\% in the later ones, ${ }^{39}{ }^{41}$ and also the use of quality adjusted lifeyears saved in two of them. ${ }^{39}{ }^{41}$

Among community based interventions, Action Heart has reported on the cost effectiveness of its cardiovascular risk reduction programme in relation to smoking. ${ }^{13}$ This project, which took place in the UK from 1991-1995, had modest intervention costs, $\sim \$ 187150$, and reported a reduction in adult smoking prevalence of 3.4 percentage points in the two intervention communities, and an increase of 1.6 percentage points in the reference community. Cost effectiveness ratios were $\sim \$ 53$ per life-year gained, without discounting, and $\sim \$ 201$ per life-year gained discounted at $6 \%$.

These impressive results must be tempered by the paucity of detail provided about the content of the low cost, community based intervention, and also by the lack of comparability in baseline smoking prevalence and socioeconomic indicators between the two intervention communities and the reference community, with the reference community having a higher prevalence of smoking $(36.4 \% \mathrm{v}$ $32.2 \%)$ and lower socioeconomic indicators. ${ }^{42}$ It seems likely that secular trends may have played a major role in the changes in smoking prevalence which occurred during this project. ${ }^{42}$ Similar trends in smoking prevalence were seen in the comparison counties in Heartbeat Wales between 1985 and 1990, and in the UK between 1996 and 2001. ${ }^{73}$

Cost effectiveness ratios, in terms of costs per working lifeyear saved, have been reported for Heartbeat Wales in relation to its smoking reduction programme, $\sim \$ 13-\$ 133$, but these analyses assumed no change in prevalence in the absence of the intervention. ${ }^{10}$ We note that during that programme, smoking prevalence decreased slightly more in the comparison counties than in Wales, and analyses at both individual and community levels showed no significant intervention effect for smoking, precluding a cost effective analysis of this aspect of Heartbeat Wales as a research project. $^{7}$

The cost effectiveness of a one year community antismoking campaign targeted at Turkish speaking people in London has also been reported. ${ }^{34}$ However, this was a prepost design with no comparison group, so that the estimates of cost per life-year gained without discounting, $\sim \$ 173$ (range \$55-\$633), do not take into account potential secular changes in smoking prevalence in the absence of the intervention.

The cost effectiveness of smoking cessation programmes, conducted as part of broader community based interventions, has been reported from four studies, ${ }^{14-16}{ }^{29}$ but for only one of these, the Stockholm Quit and Win Contest, were the results reported in terms of costs per life-year saved. ${ }^{29}$ This contest was part of a countywide intervention and combined a national mass media programme with countywide recruitment of participants through local organisations. The cost effectiveness analysis used intervention and evaluation costs, and estimates of the number of quitters based on reported quit rates at a 12 month follow up survey among participants. The cost per life-year saved, discounted at 5\%, ranged from $\$ 1671$ to $\$ 3749$.

Among the other community based based projects with economic analyses, the cost effectiveness of the North Karelia project's 1972-1977 hypertension control programme, discounted at $5 \%$, was $\sim \$ 16568,{ }^{8}$ while that of the first six years (1985-1990) of the Norsjo project's cholesterol lowering programme, discounted at 5\%, was $\sim \$ 3168-\$ 7776 .{ }^{11}$ Reports of the cost effectiveness of other hypertension and cholesterol screening and treatment programmes have shown a wide range of values, , $^{38} 4445$ with some cholesterol lowering programmes having cost effectiveness ratios greater than $\$ 100000$ per life-year saved. ${ }^{38} 45$

\section{What this paper adds}

Among 32 community based trials, undertaken since 1972, which included smoking reduction as one of their aims, cost effectiveness analyses, as dollars per life-year saved, have been reported by four, only two of which concerned smoking. Although these latter studies both noted favourable cost effectiveness ratios, methodological issues within each make comparisons with other health related interventions difficult.

This report of the cost effectiveness of a community based smoking cessation research project, targeted to women, shows cost effectiveness ratios, as dollars per life-year saved, which compare favourably to other smoking cessation interventions for women, such as physician advice, adjuvant use of nicotine gum, or the transdermal nicotine patch. These findings should encourage further research into community based interventions to reduce smoking.

We conclude that compared to other smoking cessation strategies, such as physician advice, adjuvant use of nicotine gum or the transdermal nicotine patch, or community based quit and win contests, the Breathe Easy research project was economically attractive. As a research project, costs included intervention costs, evaluation costs, and indirect costs. For a non-profit agency interested solely in funding a similar community based smoking reduction intervention, without the evaluation costs associated with a research project, but with modest indirect costs, such an investment would be more cost effective than many other secondary disease prevention strategies, such as the control of hypertension or hypercholesterolemia. ${ }^{3844}$

\section{ACKNOWLEDGEMENTS}

We thank Alison Bell, BA, for her invaluable help in abstracting and categorising the original cost data for these analyses, and Joan $M$ Skelly, MS, for the population estimates of the numbers of never, former, light, and heavy smokers. Supported by the National Institutes of Health, grants HL40685 and CA22435.

\section{Authors' affiliations}

R H Secker-Walker*, R R Holland, C M Lloyd, D Pelkey, B S Flynnt, The Office of Health Promotion Research, University of Vermont, Burlington, Vermont, USA

* Also the Vermont Cancer Center, University of Vermont †Also the Vermont Cancer Center, and the Department of Family Practice, University of Vermont

Preliminary results of the cost effectiveness of the Community Coalitions to Help Women Quit Smoking Project were part of an invited presentation to the University of Edinburgh, Department of Community Health Sciences Seminar Series, 3 May 1999, Edinburgh, UK

\section{REFERENCES}

1 Weinstein MC. Challenges for cost-effectiveness research. Med Decision Making 1986;77:162-5.

2 Phillips KA, Holtgrave DR. Using cost-effectiveness/cost benefit analysis to allocate health resources: a level playing field. Am J Prev Med 1997;13:18-25.

3 Gold MR, Siegel JE, Russell LB, Weinstein MC, eds. Cost-effectiveness in health and medicine. New York: Oxford University Press, 1996.

4 Luce BR, Simpson K. Methods of cost-effectiveness analysis: areas of consensus and debate. Clinical Therapeutics 1995;17:109-25.

5 Secker-Walker RH, Gnich W, Platt S, et al. Community interventions for reducing smoking among adults (Cochrane Review). Cochrane Database Syst Rev. 2002;(3): CD001745, PMID, 12137631.

6 Puska P, Nissinen A, Tuomilehto J, et al. The community-based strategy to prevent coronary heart disease: conclusions from the ten years of the North Karelia project. Annu Rev Public Health 1985;6: 147-93.

7 Tudor-Smith C, Nutbeam D, Moore L, et al. Effects of Heartbeat Wales programme over five years on behavioral risks for cardiovascular disease: 
quasi-experimental comparison of results from Wales and a matched reference area. BMJ 1998;346:818-22.

8 Nissinen A, Tuomilehto J, Kottke TE, et al. Cost-effectiveness of the NorthKarelia hypertension program 1972-1977. Med Care 1986;24:767-80.

9 Kottke TE, Puska P, Feldman R, et al. A decline in earnings losses associated with a community-based cardiovascular disease prevention project. Med Care 1982;20:663-75.

10 Phillips CJ, Prowle MJ. Economics of a reduction in smoking: case study from Heartbeat Wales. J Epidemiol Community Health 1993:47:215-23.

11 Lindholm L, Rosen M, Weinehall L, et al. Cost effectiveness and equity of a community based cardiovascular disease prevention programme in Norsjo, Sweden. J Epidemiol Community Health 1996;50:190-5.

12 Lindholm L, Rosen M, Hellsten G. Are people willing to pay for a communitybased preventive program. Int J Technol Assess Health Care 1994; 10:317-24.

13 Baxter T, Milner P, Wilson K, et al. A cost effective, community based heart health promotion program in England: prospective comparative study. BM 1997:315:582-5.

14 Altman DA, Flora JA, Fortmann SP, et al. The cost-effectiveness of three smoking cessation programs. Am J Public Health 1987;77:162-5.

15 Nelson DJ, Lasater TM, Nikian M, et al. Cost-effectiveness of different recruitment strategies for self-help smoking cessation programs. Health Educ Res 1989:4:79-85.

16 Mudde AN, de Vries H, Strecher VJ. Cost-effectiveness of smoking cessation modalities: comparing apples with oranges? Prev Med 1996;25:708-16.

17 Secker-Walker RH, Flynn BS, Solomon L, et al. Helping women quit smoking: Results of a community intervention program. Am J Public Health 2000;90:940-6.

18 Secker-Walker RH, Flynn BS, Solomon $\sqcup$, et al. Helping women quit smoking: baseline observations for a community health education program. Am J Prev Med 1996;12:367-77

19 Secker-Walker RH, Solomon U, Flynn BS, et al. Comparisons of the smoking cessation counseling activities of six types of health Professionals. Prev Med 1994;23:800-8

20 Solomon L, Secker-Walker RH, Flynn BS, et al. Proactive peer support by telephone to help women quit smoking. Health Educ Res Theory Pract 1996:11:377-81.

21 Secker-Walker RH, Solomon $\amalg$, Geller BM, et al. Modeling smoking cessation: exploring the use of a videotape to help pregnant women quit smoking. Womens Health 1997;25:23-35.

22 Secker-Walker RH, Dana G, Solomon $\amalg$, et al. The role of health professionals in a community-based program to help women quit smoking. Prev Med 2000;30:126-37.

23 Consumer Price Index. ftp://ftp.bis.gov/pub/special.requests/cpi/cpiai.txt.

24 Shah BV, Barnwell BG, Bieler GS. SUDANN user's manual, Release 7.5. Research Triangle Park, North Carolina: Research Triangle Institute, 1997.

25 Microsoft Access 2002, Copyright Microsoft Corporation 1992-2001.

26 Rogers RG, Powell-Griner E. Life expectancies of cigarette smokers and nonsmokers in the United States. Soc Sci Med 1991;32:1151-9.
27 US Department of Health and Human Services. Vital statistics of the United States, 1986 life rables, DHHS Publication No.(PHS) Hyattsville, Maryland, October, 1988:88-147.

28 Lipscomb J, Weinstein MC, Torrance GW. Time preference. In: Gold MR Siegel JE, Russell LB, Weinstein MC, eds. In: Cost-effectiveness in health and medicine. New York: Oxford University Press, 1996:214-46.

29 Tillgren $P$, Rosen $M$, Haglund BJA, et al. Cost-effectiveness of a tobacco 'Quit and Win' contest in Sweden. Health Policy 1993;26:43-53.

30 Wonderling $D$, Langham S, Buxton $M$, et al. What can be concluded from the Oxcheck and British family heart studies: commentary on cost effectiveness analyses. BMJ 1996;312:1274-8.

31 United States Life Tables, 2000. NVSR Volume 51, Number 3. (PHS) 2003-, 1120.

32 The COMMIT Research Group. Community intervention trial for smoking cessation (COMMIT): II. Changes in adult cigarette smoking prevalence. Am J Public Health 1995;85:193-200.

33 Hancock L, Sanson-Fisher R, Perkins J, et al. Effect of a community action program on adult quit smoking rates in rural Australian towns: the CART project. Prev Med 2001;32:1 18-27.

34 Stevens W, Thorogood M, Kayikki S. Cost-effectiveness of a community antismoking campaign targeted at a high risk group in London. Health Promotion International 2002;17:43-50.

35 Donner A, Klar N. Statistical considerations in the design and analysis of community intervention trials. J Clin Epidemiol 1996:49:435-9.

36 Murray DM. Design and analysis of group-randomized trials. New York: Oxford University Press, 1998.

37 Oster G, Huse DM, Delea TE, et al. Cost-effectiveness of nicotine gum as an adjunct to physician's advice against cigarette smoking. JAMA 1986;256:1315-18.

38 Cummings SR, Rubin SM, Oster G. The cost-effectiveness of counseling smokers to quit. JAMA 1989;261:75-9.

39 Fiscella K, Franks P. Cost-effectiveness of the transdermal patch as an adjunct to physicians' smoking cessation counseling. JAMA 1996;275:1247-51.

40 O'Loughlin JL, Paradis G, Gray-Donald K, et al. The impact of a communitybased heart disease prevention program in a low-income, inner-city neighborhood. Am J Public Health 1999;89:1819-26.

41 Cromwell J, Bartosch WJ, Fiore MC, et al. Cost-effectiveness of the clinical practice recommendations in the AHCPR guideline for smoking cessation. JAMA 1997;278:1759-66.

42 Smith GD, Ebrahim S. Community based heart health promotion project in England: authors' conclusions are unjustified and misleading. Letter to the editor. BMJ 1998;316:705.

43 Lader D, Meltzer H. Smoking behaviour and attitudes, 2001. London: The Office of National Statistics, Her Majesty's Stationary Office, 2002:21.

44 Weinstein MC, Stason WB. Cost-effectiveness of interventions to prevent or treat coronary heart disease. Annu Rev Public Health 1985;6:41-63.

45 Kristiansen IS, Eggen AE, Theile DS. Cost effectiveness of incremental programmes for lowering serum cholesterol concentration: is individual intervention worth while? BMJ 1991;302:1119-22. 